\title{
Influencia del cloruro de calcio en la textura de las aceitunas, tipo negras naturales variedad criolla (Olea europaea), en la etapa fermentativa
}

\author{
Influence of calcium chloride in the texture of olives, type \\ natural black creole variety (Olea europaea), in the fermentative stage
}

\section{Clavijo Koc ${ }^{1}$; W. Garragate Rospigliosi ${ }^{2}$; M. Gallegos Arata ${ }^{3}$; C. Villalobos Ochoa $^{4}$; R. Porturas Olaechea ${ }^{5}$}

\begin{abstract}
Resumen
El trabajo presenta los resultados del control de $\mathrm{pH}$, acidez y contenido de dióxido de carbono durante la fermentación de aceitunas negras naturales, aplicando cloruro de calcio e inóculos de bacterias lácticas nativas en la salmuera inicial del fruto y utilizando una concentración promedio de cloruro de sodio de $11,42 \%$, con la finalidad de evaluar la influencia de este compuesto en la textura del fruto durante la fermentación. Se observó que en todos los ensayos se alcanzan valores de $\mathrm{pH}$ alrededor de 3,5 y una acidez entre 1,7 y 2 expresado como porcentaje de ácido láctico por $100 \mathrm{ml}$ de salmuera. Dichos valores fueron considerados normales para este tipo de preparación con aceitunas de esta variedad, indicando que la aplicación del cloruro de calcio no interfirió en la fermentación. La textura se evaluó instrumentalmente, observándose mejora significativa en ella cuando se aplicó cloruro de calcio.
\end{abstract}

Palabras clave: aceitunas negras naturales; alambrado; inóculos de bacterias lácticas.

\begin{abstract}
This research presents the results of $\mathrm{pH}$, acidity and carbon dioxide content monitoring during the fermentation of natural black olives, applying calcium chloride and inocula of native lactic bacteria in the initial brine of the fruit and using an average concentration of sodium chloride of $11,42 \%$, in order to evaluate the influence of this compound in the texture of the fruit during fermentation. It was observed that in all trials values of $\mathrm{pH}$ around 3,5 are reached and an acidity between 1,7 and 2 expressed as percentage of lactic acid per $100 \mathrm{ml}$ of brine. These values were considered normal for this type of preparation with olives of this variety, indicating that the application of calcium chloride did not interfere with fermentation. The texture was evaluated instrumentally, showing significant improvement in it when calcium chloride was applied.
\end{abstract}

Keywords: natural black olives; fish eye; lactic bacteria inocula.

\section{Introducción}

La elaboración de la aceituna de mesa en la forma de negra natural, es de gran importancia en la zona sur del Perú, pues representa la producción de alrededor del 70 $\%$ de la aceituna de mesa en esta localidad, y un $40 \%$ del total de las exportaciones de aceitunas preparadas o conservadas, siendo la variedad más utilizada la criolla o sevillana (Olea europaea).
La aceituna, al ser sometida a una fermentación natural anaeróbica, producto del estado de madurez en la que ingresa y de la producción de ácido durante la fermentación, sufre una pérdida de textura relacionada con el metabolismo de las sustancias pécticas presentes en las células de la pulpa, como resultado de la presencia de enzimas tanto de la pulpa de las aceitunas como de los microorganismos aislados en las salmueras. Por lo tanto,

\footnotetext{
1 Bióloga. Módulo de Servicios Tacna - CITE agroindustrial. Universidad Nacional Agraria La Molina, Lima (Perú). Email: claudiavck@hotmail.com 2 Ingeniero en Industrias Alimentarias. Módulo de Servicios Tacna-CITE agroindustrial. Universidad Nacional Agraria La Molina, Lima (Perú). Email: wgarrate@olivosbiondi.com

3 Ingeniero en Industrias Alimentarías. Biondi y Cia de Tacna SAC, Universidad Nacional Agraria La Molina, Lima (Perú). Email: marthagallegosarata@ gmail.com

4 Ingeniero en Industrias Alimentarias. Biondi y Cia de Tacna SAC, Universidad Nacional Agraria La Molina, Lima (Perú). Email: Carla_mvo@ gmail.com

5. Master of Science. Profesor Principal. Facultad de Pesquería. Universidad Nacional Agraria La Molina, Lima (Perú). Email: rporturas@lamolina. edu.pe
} 
la textura es un parámetro de calidad que define el precio de este tipo de preparación.

En ese sentido, varios intentos de definir la textura de un alimento han culminado en un acuerdo internacional con el desarrollo de la Norma Internacional ISO 5492, donde la textura se define como "todos los atributos mecánicos, geométricos y superficiales de un producto, perceptible por medio de receptores mecánicos, táctiles y, si es apropiado, visuales y auditivos.” (7) Para mejorar la textura del fruto se utiliza cloruro de calcio, en algunos casos se aplica al inicio del proceso (5) y en otros al final de la fermentación (7) obteniendo una mejora significativa en la evaluación sensorial, ya que el cloruro del calcio causa un sustancial incremento de la firmeza de la aceituna madura (8).

El presente estudio tuvo como objetivos evaluar la influencia del cloruro de calcio en la mejora de textura del producto y en el proceso fermentativo aplicándolo en la salmuera inicial. Para ello, la textura fue determinada instrumentalmente mediante la fuerza necesaria para empujar una sonda de metal o penetrómetro en un fruto (5), además de mediciones de $\mathrm{pH}$, índice de acidez y contenido de dióxido de carbono, como pruebas comparativas de estudio y análisis.

\section{Materiales y métodos}

\section{Lugares de ejecución}

Las aceitunas provinieron del fundo San Martín de Porres

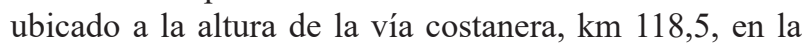
irrigación La Yarada en Tacna Perú, propiedad de la Empresa Biondi y la Compañía De Tacna SAC, ubicadas en las coordenadas: latitud $18^{\circ} 12^{\prime} 41.3^{\prime \prime}$ y longitud $70^{\circ} 31^{\prime} 25.9^{\prime \prime}$; en alianza con el Centro de Innovación Tecnológica (CITE agroindustrial), Módulo de Servicios Tacna.

Los análisis físicos y químicos del presente estudio se llevaron a cabo en los laboratorios de CITELAB del Módulo de Servicios Tacna, CITE Agroindustrial. Panamericana Sur, km 1303 - Ciudadela ZOFRATACNAPerú, Dirección postal actual $\mathrm{N}^{\circ}$ 331. Las pruebas de comprobación finales y análisis de calidad se desarrollaron en los laboratorios de La Molina Calidad Total de la Universidad Nacional Agraria La Molina.

\section{Materiales}

Los frutos empleados en todas las experiencias han sido de la variedad criolla, conocida también como sevillana (Olea europaea), maduros, procedentes de los campos de cultivo de la empresa, cosechados a inicios del mes de junio del año 2012. El índice de madurez de la aceituna utilizada en la experimentación fue de 4,95, que se determinó siguiendo el procedimiento establecido por la Estación de Olivicultura de Jaén, el mismo que se basa en la apreciación del color de la aceituna sobre una muestra de 100 aceitunas (9).

\section{Tanques de fermentación}

Para llevar a cabo la experimentación se utilizaron tanques de fibra de vidrio con resina poliéster de 1200 litros de capacidad en volumen, los cuales contienen cada uno $703 \mathrm{~kg}$ de aceituna, con tapa y con una salida pequeña para los gases de la fermentación. La aceituna se cubre con salmuera y en el mismo tanque se lleva a cabo el proceso de fermentación.

\section{Métodos}

Las determinaciones químicas de índice de acidez, porcentaje de cloruros, contenido de dióxido de carbono y pH se realizaron según los métodos habituales reportados por Fernández (1985) y Garrido (1997).

\section{Determinación del pH}

Para medir el pH se utiliza un potenciómetro portátil marca Hanna modelo HI 8724, procediendo a pesar $10 \mathrm{~g}$ de pulpa de aceituna a las cuales se adiciona la cantidad necesaria de agua destilada hasta cubrir el bulbo del $\mathrm{pH}$ metro. La cantidad de agua que se incorpore debe ser como máximo nueve veces la cantidad de la muestra, para no alterar el valor del $\mathrm{pH}$.

\section{Determinación de la acidez}

Para determinar la acidez se aplica la valoración volumétrica del contenido ácido con hidróxido de sodio al $0.2 \mathrm{~N}$ sobre $10 \mathrm{ml}$ muestra de salmuera de aceituna y se expresa en porcentaje de ácido láctico, utilizando como indicador fenolftaleína (3).

\section{Determinación del porcentaje de cloruros}

Se aplica el método indicado por Garrido (1997), basado en el método de Mohr, por valoración volumétrica con nitrato de plata $0.1 \mathrm{~N}$, de $0.5 \mathrm{ml}$ de muestra diluida en $100 \mathrm{ml}$ de agua, utilizando como indicador solución del cromato de potasio al $5 \%$.

\section{Determinación el contenido de dióxido de carbono}

Se aplica el método desarrollado por el Instituto de la Grasa (10), el cual se basa en añadir un reactivo ácido (solución ácida de fosfato) a la muestra, logrando que se desprenda de ella el $\mathrm{CO}_{2}$ disuelto. Si este se pone en contacto con una solución valorada de $\mathrm{NaOH}$ ocurre la siguiente reacción:
$2 \mathrm{NaOH}+\mathrm{CO}_{2}+\mathrm{H}_{2} \mathrm{O}$
$\mathrm{Na}_{2} \mathrm{CO}_{3}+2 \mathrm{H}_{2} \mathrm{O}$

Por diferencia entre la concentración inicial de $\mathrm{NaOH}$ y la que presenta, una vez que todo el $\mathrm{CO}_{2}$ separado se haya absorbido, se puede conocer la proporción que había del mismo en la salmuera.

Debe evitarse la interferencia del $\mathrm{Na}_{2} \mathrm{CO}_{3}$ formado, lo que se consigue desplazando al ion sodio por el bario, mediante la adición de $\mathrm{BaCl}_{2}$ que origina un precipitado blanco:

$$
\mathrm{BaCl}_{2}+\mathrm{Na}_{2} \mathrm{CO}_{3} \quad \mathrm{BaCO}_{3}+2 \mathrm{NaCl}
$$

Una vez precipitado, la valoración de la solución de $\mathrm{NaOH}$ final se realiza sin problemas, utilizando fenolftaleínathimolftaleína como indicador y $\mathrm{HCl}$ como valorante. Se expresa en $\mathrm{mg}$ de $\mathrm{CO}_{2}$ por cada $100 \mathrm{ml}$ de salmuera.

\section{Análisis de textura}

Para la determinación de textura se utilizó un penetrómetro PCE- PTR 200, tomando como base el procedimiento indicado (4), que consiste en aplicar la medida de textura en 40 aceitunas obtenidas de 500 gr de la muestra extraída del fermentador, registrando la medida de la fuerza aplicada expresada en Newton por 
el punzón del dinamómetro en tres lugares diferentes del fruto; luego, se toma un promedio por cada aceituna, este promedio es el que se considera como la medida de la fuerza aplicada expresada en Newton, para expresarla como presión el valor anterior se divide entre el área del punzón y se obtiene la medida expresada en Newton $/ \mathrm{cm}^{2}$.

\section{Análisis estadístico}

El análisis estadístico se aplicó a los resultados obtenidos de la textura, aplicando el análisis de varianza (ANOVA) a fin de determinar la existencia de diferencia significativa entre los tratamientos, aplicando un diseño aleatorizado a un criterio en los resultados registrados, siguiendo las recomendaciones de Delgado (2010). El programa utilizado fue el STAT Graphics versión 16.

\section{Experimentación}

Las aceitunas fueron colocadas en salmueras iguales a las utilizadas tradicionalmente en el procesamiento de aceituna negra madura. Las características iniciales de las salmueras y las variaciones experimentales se muestran en la Tabla 1.

Al cabo de cuatro meses en fermentación se procedió a la selección y medida de textura del fruto y a hacer la comparación respectiva.

\section{Resultados y discusión}

Evolución del pH y acidez durante el proceso fermentativo

Uno de los principales parámetros de control en la producción comercial de aceitunas negras durante la etapa de fermentación es la evolución del pH (3 y 4). En esta experimentación no se aciduló la salmuera de inicio ( $11.42 \%$ de $\mathrm{NaCl}$ ), la cual empieza en $\mathrm{pH}$ : 6.5, observándose que la evolución del $\mathrm{pH}$ en el tanque que solo contiene $\mathrm{ClCa}_{2} 0.3 \%$ (muestra TL0-000) fue más lenta que las otras muestras. Inclusive la caída del $\mathrm{pH}$, luego de 30 días de fermentación, se estabiliza en valores cercanos a 3.5. Estos valores en descenso del $\mathrm{pH}$, presentados en la Fig. 1, nos indicó la presencia de una fermentación láctica, pues se observó que a los 134 días se tuvo los mismos valores de $\mathrm{pH}$ en todos los tratamientos. El rápido descenso del $\mathrm{pH}$ se debió a la alta producción de ácido en las salmueras de todas las muestras, que se vio reflejada con los bajos valores de acidez obtenida por la participación de las bacterias lácticas (1). Los valores obtenidos fueron los normales para la época en todos los tanques, lo que significó que la aplicación de cloruro de calcio no tuvo influencia negativa en el desarrollo del pH final del producto, así como en los inóculos y en las bacterias lácticas nativas.

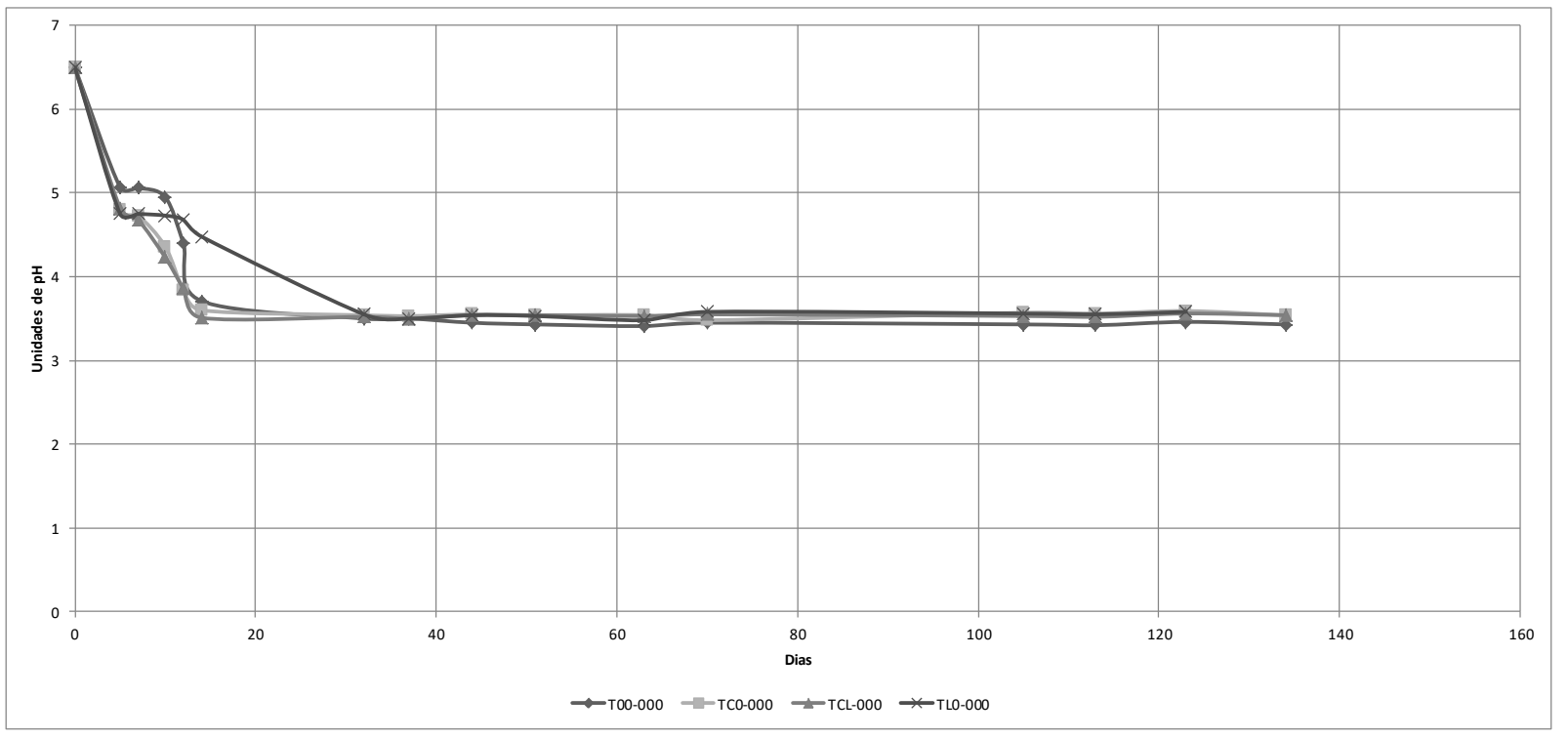

Figura 1. Evolución del pH durante el periodo fermentativo.

Tabla 1. Características de los experimentos

\begin{tabular}{|c|c|c|c|}
\hline Código de Experimentación & $\begin{array}{c}\text { Concentración inicial de } \\
\mathrm{NaCl}(\%)\end{array}$ & $\begin{array}{c}\text { Concentración inicial de } \\
\mathrm{CaCl}_{2}(\%)\end{array}$ & Aplicación de inóculo \\
\hline T00-000 & 11.42 & - & No \\
\hline TC0-000 & 11.42 & - & $\mathrm{Si}$ \\
\hline TCL-000 & 11.42 & $0.3 \%$ & $\mathrm{Si}$ \\
\hline TL0-000 & 11.42 & $0.3 \%$ & No \\
\hline
\end{tabular}


La evolución de la acidez en los tanques de fermentación se reporta en la Fig. 2 observándose que fue similar en todos los tanques, tanto en aquellos en los que se aplicó cultivo láctico, así como en los que se agregó $\mathrm{ClCa}_{2}$. En cuanto a los valores finales de acidez, los valores obtenidos en los tanques sin inóculo (muestras T00-000 y TL0-000) son iguales con valores de $1.93 \%$ de acidez. A diferencia de aquellos en los tanques con inóculo (muestra TC0-000 y TCL-000) que alcanzaron valores de acidez del orden de $1.71 \%$ durante la fermentación. Lo que significó que la adición del $\mathrm{ClCa}_{2} 0.3 \%$ no evidencio diferencias entre los valores de acidez y $\mathrm{pH}$ finales de las otras muestras, así como de los usualmente encontrados en la industria de la producción de aceitunas negras en el sur del Perú (7).

\section{Evolución del contenido de dióxido de carbono en la} salmuera durante la fermentación

En la Fig. 3 se reporta el control de la producción de dióxido de carbono a lo largo del proceso fermentativo, observándose que la evolución no fue uniforme, además de variable en función del tiempo. Se fue incrementando hasta valores cercanos a $160 \mathrm{mg} / 100 \mathrm{ml}$ de salmuera a los 125 días, casi al final de la fermentación para todas las muestras ensayadas, coincidiendo con el incremento de temperatura por el cambio de estación. La experimentación se inició a mediados del mes de junio y se dio por concluida a finales del mes de octubre del año 2012. Sin embargo, se observó que los valores de contenido de dióxido de carbono al final de la fermentación fueron similares en casi todos los tanques, con valores entre 118 a $125 \mathrm{mg}$ de $\mathrm{CO}_{2} / 100 \mathrm{ml}$ de salmuera a los 130 días de fermentación.

\section{Evaluación de la textura al final de la fermentación}

Se procedió a realizar el control de la textura de las aceitunas aplicando las indicaciones de uso del penetrómetro (4) y (6) utilizando el punzón con diámetro de $6 \mathrm{~mm}$. Los promedios de medición por tratamiento se muestran en la Tabla 2.

Aplicando el análisis de varianza para determinar si hubo diferencia significativa entre los tratamientos,

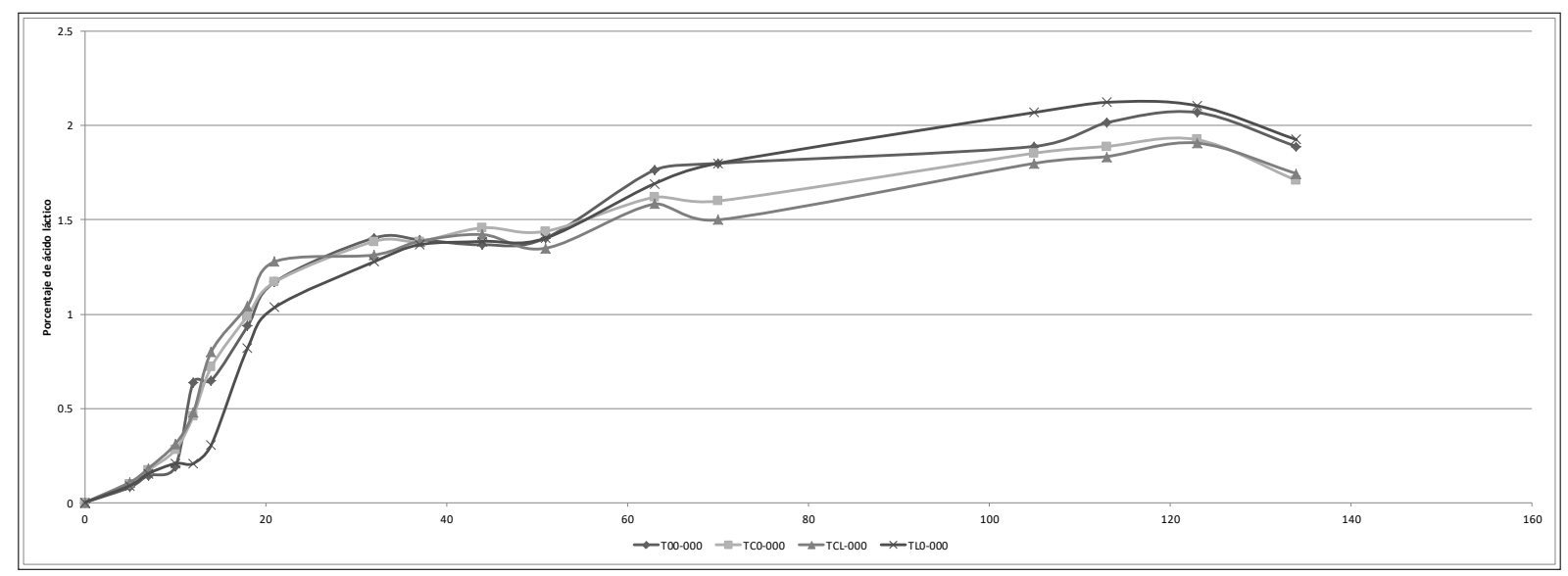

Figura 2. Evolución de la acidez libre durante la fermentación.

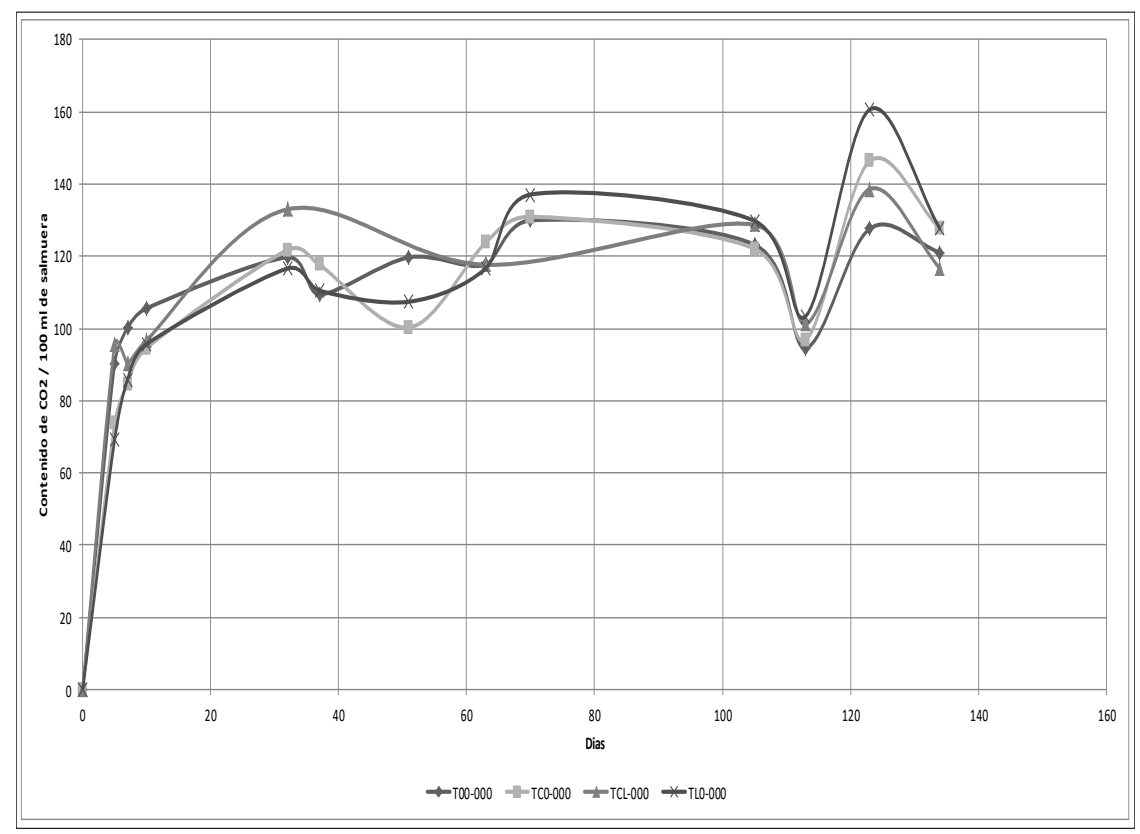

Figura 3. Evolución del contenido del dióxido de carbono en la salmuera. 
Tabla 2. Valores de textura por cada muestra $\left(\mathrm{Newton} / \mathrm{cm}^{2}\right)$

\begin{tabular}{|c|c|c|c|c|}
\hline Código & T00-000 & TC0-000 & TCL-000 & TL0-000 \\
\hline Newton/cm2 & 10.01 & 10.16 & 11.71 & 12.42 \\
\hline $\begin{array}{c}\text { Grupo de Análisis } \\
\text { de Varianza }\end{array}$ & $\mathrm{a}$ & $\mathrm{a}$ & $\mathrm{b}$ & $\mathrm{b}$ \\
\hline
\end{tabular}

Tabla 3. Porcentaje de alambrado al final de la fermentación

\begin{tabular}{|c|c|}
\hline $\begin{array}{c}\text { Código de } \\
\text { experimentación }\end{array}$ & \% de alambrado \\
\hline T00-000 & $8,61 \%$ \\
\hline TC0-000 & $5,16 \%$ \\
\hline TCL-000 & $4,35 \%$ \\
\hline TL0-000 & $6,89 \%$ \\
\hline
\end{tabular}

se determinó que entre los tanques experimentales en los cuales no se aplicó cloruro de calcio, identificados como Grupo a, no se encontró diferencia significativa entre ellos. En los experimentos en los cuales se aplicó cloruro de calcio, identificados como Grupo b, tampoco hubo diferencia significativa entre ellos. Sin embargo, al comparar el Grupo a con el Grupo b, se concluyó que sí existió diferencia significativa, observándose que la textura de la aceituna muestreada del Grupo b fue mayor a la del Grupo a (2).

En función a estos resultados, se determinó que hubo diferencias entre los tratamientos en los cuales se aplicó cloruro de calcio, en comparación con los que no se les aplicó dicho aditivo, notándose una mejora importante en la textura final de la aceituna luego de la fermentación. Por ejemplo la muestra T00-000 sin adición de $\mathrm{ClCa}_{2}$ e inóculo fue la más blanda con 10.01 newton $/ \mathrm{cm}^{2}$, a diferencia de la muestra TL0-000 con $0.3 \%$ de $\mathrm{ClCa}_{2}$ e inóculo que alcanzó la mayor firmeza con 12.42 newton/ $\mathrm{cm}^{2}$.

\section{Evaluación del contenido de alambrado al final de la fermentación}

El alambrado llamado también fish eye es una de las mayores alteraciones que se encuentran en la fermentación en el producto final, depreciándolo (10). Por ello, al momento de la clasificación se retiran los frutos que presentan esta alteración, sobre todo en aceitunas que hayan sufrido daño durante la cosecha. La Tabla 3 presenta el resumen del porcentaje de alambrado encontrado para cada tratamiento, resultante de la clasificación de 100 $\mathrm{kg}$ de muestra de aceituna, al final de la fermentación. Se aprecia que en los tanques donde se aplicó los inóculos más el $\mathrm{ClCa}_{2}$ (muestra TL0-000) fueron los que presentaron menor porcentaje de alambrado, con valores del $4.35 \%$, a diferencia de la muestra testigo (T00-000) que alcanzó niveles de alambrado del orden del 8.61 $\%$. Asimismo, se observó que esta muestra TL0-000 coincidentemente menores valores de dióxido de carbono al final de la fermentación. Los porcentajes menores de fish eye se relacionan con un menor porcentaje de dióxido de carbono disuelto en salmuera, tal como se aprecia en la Fig. 3, debido a la predominancia de la fermentación por bacterias lácticas (3).

Al calcularse la desviación estándar de los resultados se obtuvo una diferencia, con relación al promedio de aceituna alambrada del $1,90 \%$, lo que significó que la aplicación de cultivos lácticos logró $1,90 \%$ menos de aceituna con el defecto llamado fish eye.

\section{Conclusiones}

A partir de los resultados de la experimentación, se pudo concluir que la aplicación de niveles de $0,3 \%$ de cloruro de calcio en la salmuera de inicio no afectó el normal desarrollo del proceso fermentativo, obteniéndose valores similares a los alcanzados por el método tradicional. Se demostró que el cloruro de calcio para este tipo de preparación de aceituna negra natural mejoró la textura del producto final, siendo la desviación estándar de los promedios de $1,18 \mathrm{Newton} / \mathrm{cm}^{2}$, sin incrementar los valores de alambrado. Se observó también que la aplicación de inóculos disminuyó el porcentaje de alambrado, obteniéndose una desviación estándar de los promedios de aceituna alambrada de 1,90\%.

\section{Literatura citada}

Delgado Tello, Pelayo. 2010. Estadística y Probabilidad. Tacna: Fondo Editorial Universidad Privada de Tacna.

Fernández Diez, M. J. 1985. Biotecnología de la Aceituna de Mesa. Sevilla: Instituto de la Grasa y sus Derivados (C.S.I.C).

Garrido Fernández A. 1997. Table Olives. Chapman \& Hall. 